Disclosure of Interests: Sinead Maguire: None declared, Gillian Fitzgerald Grant/research support from: Recipient of the Bresnihan-Molloy Scholarship funded by AbbVie, Claire Sheehy: None declared, Finbar Barry O'Shea: None declared

DOI: 10.1136/annrheumdis-2019-eular.2501

\section{FRI0681 ASSOCIATION OF BODY COMPOSITION, PHYSICAL ACTIVITY AND PHYSICAL PERFORMANCE WITH KNEE CARTILAGE THICKNESS AND SUBCHONDRAL BONE AREA IN YOUNG ADULTS}

Tao Meng ${ }^{1}$, Benny Antony ${ }^{1}$, Alison Venn ${ }^{1}$, Felix Eckstein ${ }^{2,3}$, Flavia Cicuttini ${ }^{4}$ Lyn March $^{5}$, Marita Cross ${ }^{5}$, Terence Dwyer ${ }^{1,6}$, Graeme Jones ${ }^{1}$, Laura Laslett ${ }^{1}$, Changhai Ding $1,7 .{ }^{1}$ Menzies Institute for Medical Research, University of Tasmania, Hobart, Australia; ${ }^{2}$ Institute of Anatomy, Paracelsus Medical University, Salzburg, Austria; ${ }^{3}$ Chondrometrics GmbH, Ainring, Germany; ${ }^{4}$ Department of Epidemiology and Preventive Medicine, Monash University, Melbourne, Australia; ${ }^{5}$ Institute of Bone and Joint Research, University of Sydney, Sydney, Australia; ${ }^{6}$ The George Institute for Global Health, Nuffield Department of Obstetrics and Gynaecology, University of Oxford, Oxford, United Kingdom; ${ }^{7}$ Clinical Research Centre, Zhujiang Hospital, Southern Medical University, Guangzhou, China

Background: Body composition, physical activity and physical performance may play roles in the incidence of knee osteoarthritis. However, the effects of body composition, physical activity and physical performance on knee cartilage thickness and subchondral bone area in young adults were unknown.

Objectives: To describe associations of body composition, physical activity and physical performance with knee cartilage thickness and subchondral bone area in young adults.

Methods: Body composition, physical activity and physical performance were measured 4-5 years prior to knee magnetic resonance imaging (MRI). Cartilage thickness and subchondral bone area of patella and lateral/medial femorotibial compartment were measured quantitatively from MRI. Total knee cartilage thickness was calculated as the weighted-average according to bone area of each compartment; total knee bone area was calculated as the sum of each compartment. Associations were assessed using linear regression analysis. Age, gender, height (if fat mass or lean mass was predictor) and BMI (if physical activity or physical performance measures were predictors) were examined as potential confounders and were included in the regressions. Mediator was identified using mediation analysis (Stata's medeff command).

Results: Participants were aged $31-40$ years, $48 \%$ were female $(n=186)$ Greater lean mass, but not fat mass, was positively associated with total knee cartilage thickness $(\beta=6.50 \mu \mathrm{m} / \mathrm{kg}, 95 \%$ confidence interval (Cl): 0.86 to 12.13$)$ and subchondral bone area $\left(\beta=13.66 \mathrm{~mm}^{2} / \mathrm{kg}, 95 \% \mathrm{Cl}\right.$ : 5.73 to 21.59 ). Physical performance measures were positively associated with knee cartilage thickness (long jump: $\beta=2.36 \mu \mathrm{m} / \mathrm{cm}, 95 \% \mathrm{Cl} 0.68$ to 4.04; hand grip strength: $7.65 \mu \mathrm{m} / \mathrm{kg}, 1.53$ to 13.77 ; physical work capacity: $1.04 \mu \mathrm{m} /$ watt, 0.27 to 1.81 ) and subchondral bone area (long jump: $\beta=4.25 \mathrm{~mm}^{2} / \mathrm{cm}, 95 \% \mathrm{Cl} 1.01$ to 7.50 ; hand grip strength: 19.89 $\mathrm{mm}^{2} / \mathrm{kg}, 8.23$ to 31.55 ; leg strength: $3.32 \mathrm{~mm}^{2} / \mathrm{kg}$. 1.25 to 5.40 ; physical work capacity: $3.00 \mathrm{~mm}^{2} /$ watt, 1.54 to 4.45 ). Mediation analysis suggested these associations were mediated by lean mass (effect mediated: 2995\%). Questionnaire based activity measures (including walking, moderate activity, vigorous activity and total activity) were not associated with total knee cartilage thickness or subchondral bone area.

Conclusion: Greater lean mass and better physical performance measures were associated with greater knee cartilage thickness and subchondral bone area in young adults, and the associations of physical performance were largely mediated by lean mass. These findings suggest lean mass may play an important role in maintaining knee joint health in young adults.

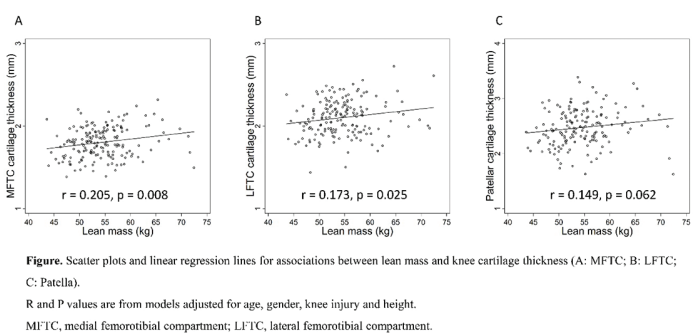

Disclosure of Interests: : Tao Meng: None declared, Benny Antony: None declared, Alison Venn: None declared, Felix Eckstein Shareholder of: Shareholder of Chondrometrics $\mathrm{GmbH}$, Consultant for: Consulting fees from Merck KGaA, Samumed LLC, Abbvie, Bioclinica, TissueGene, Servier, and Roche, Employee of: Employee of Chondrometrics GmbH, Flavia Cicuttini: None declared, Lyn March: None declared, Marita Cross: None declared, Terence Dwyer: None declared, Graeme Jones: None declared, Laura Laslett: None declared, Changhai Ding: None declared DOI: 10.1136/annrheumdis-2019-eular.1557

\section{FRI0682 LEISHMANIASIS IN PATIENTSWITH CHRONIC INFLAMMATORY DISEASE TREATED WITH IMMUNOMODULATORS. MULTICENTER ANALYSIS}

L Montolio-Chivaa ${ }^{1}$, Elia Valls-Pascual ${ }^{1}$, D Ybáñez-García ${ }^{1}$, À Martínez-Ferrer ${ }^{1}$, Marta Aguilar-Zamora ${ }^{1}$, Ana V Orenes Vera ${ }^{1}$, I Vázquez-Gómez ${ }^{1}$, A SendraGarcía $^{1}$, Jm Paredes Arquiola ${ }^{1}$, Meritxell Fernandez Matilla ${ }^{2}$, L Gómez Escolar ${ }^{3}$ José Miguel Senabre-Gallego ${ }^{3}$, J Lluch Pons ${ }^{4}$, C Campos Fernández ${ }^{5}$, M Robustillo-Villarino ${ }^{6}$, María Dolores García-Armario ${ }^{7}, S_{\text {Antón-González }}^{8}$, Ana Urruticoechea-Arana ${ }^{9}$, Isabel de la Morena ${ }^{10}$, J Fiter-Areste ${ }^{11}$, Vega Jovani ${ }^{12}$, A Martínez-Cristóbal ${ }^{13}$, Lourdes Mateo ${ }^{14}$, Sergi Ordoñez ${ }^{15}$, D Reina-Sanz ${ }^{16}$, C Vergara-Dangond ${ }^{17}$, VNúñez-Monje ${ }^{1}$, I Torner-Hernández ${ }^{1}$, Juanjo J. AlegreSancho ${ }^{1} .{ }^{1}$ Universitary Peset Doctor Hospital, Valencia, Spain; ${ }^{2}$ Arnau de Vilanova Hospital, Valencia, Spain; ${ }^{3}$ Marina Baixa Hospital, La Vila Joiosa, Spain; ${ }^{4}$ Bellvitge Hospital, Barcelona, Spain; ${ }^{5}$ General Hospital, Valencia, Spain; ${ }^{6}$ La Plana Hospital, Villarreal, Spain; ${ }^{7}$ Lluís Alcanyís Hospital, Xàtiva, Spain; ${ }^{8}$ Vall d'Hebrón Hospital, Barcelona, Spain; ${ }^{9} \mathrm{C}$ an Misses Hospital, Ibiza, Spain; ${ }^{10} \mathrm{Clinic}$ Hospital, Valencia, Spain; ${ }^{11}$ Son Espases Hospital, Mallorca, Spain; ${ }^{12}$ General Hospital, Alicante, Spain; ${ }^{13}$ Ribera Hospital, Alzira, Spain; ${ }^{14}$ Germans Trias i Pujol Hospital, Badalona, Spain; ${ }^{15}$ Arnau de Vilanova Hospital, Lleida, Spain; ${ }^{16}$ Moises Broggi Hospital, Sant Joan Despí, Spain; ${ }^{17}$ HM Sanchinarro Hospital, Madrid, Spain

Background: Patients with chronic inflammatory disease in treatment with immunosuppressants have an increased risk of opportunistic infections, including leishmaniasis.

Objectives: To describe a multicenter case series of leishmaniasis in patients with chronic inflammatory diseases treated with immunosuppressants. To analyze factors related to the infection.

Methods: Observational retrospective study. We reviewed the clinical history of patients with chronic inflammatory diseases treated with immunosuppressants, who were diagnosed with leishmaniasis between 2007 and 2018. Demographic (age, sex) and clinical (type and time of evolution of the inflammatory disease, comorbidities, current treatment, leishmaniasis form) variables were collected. Immunosuppressant withdraw, subsequent reintroduction and recurrence were recorded. We analyzed differences in clinical presentation related to anti-TNF $\alpha$ treatment. Statistical analysis were performed using SPSS 22.0 program.

Results: 55 cases were collected. $58,2 \%$ were men and the average age was 57,2 (SD 1,9) years. Twenty-one patients had spondyloarthropathy, 17 rheumatoid arthritis, 14 inflammatory bowel disease, 1 systemic lupus erythematosus, 1 Behçet and 1 uveitis. The average duration of the disease was 11,4 (SD 1,4) years and $30,9 \%$ of patients had other causes of immunosuppression. Thirty-eight patients received treatment anti-TNF $\alpha$ (19 infliximab, 11 adalimumab, 5 golimumab, 2 certolizumab and 1 etanercept), 15 with DMARD (14 methotrexate, 1 leflunomide), 1 with tocilizumab and 1 with azathioprine. $27.3 \%$ patients received corticoids. $52,7 \%$ developed cutaneous form, $38,2 \%$ visceral form, $7,3 \%$ mucocutaneous form and 1 presented visceral and cutaneous involvement. Treatment was withdrawn in 37 cases and it was reintroduced in 23 cases $(8$ anti$\mathrm{TNF} \alpha$ ). Four patients relapsed. More cases of visceral leishmaniasis were seen in patients treated with non-anti-TNF $\alpha$ drugs and in those treated with glucocorticoids. Most of the recurrences were associated with mucocutaneous form.

Conclusion: In our series, the majority of cases of leishmaniasis occurred in patients treated with anti-TNF $\alpha$, but non-anti-TNF $\alpha$ patients developed more serious forms. It's important to keep in mind this infectious complication in daily clinical practice.

Disclosure of Interests: : L Montolio-Chiva: None declared, Elia VallsPascual: None declared, D Ybáñez-García: None declared, À MartínezFerrer: None declared, Marta Aguilar-Zamora: None declared, Ana V Orenes Vera: None declared, I Vázquez-Gómez: None declared, A Sendra-García: None declared, JM Paredes Arquiola: None declared, Meritxell Fernandez Matilla: None declared, L Gómez Escolar: None declared, José Miguel Senabre-Gallego: None declared, J Lluch Pons : None declared, C Campos Fernández: None declared, M Robustillo-Villarino None declared, María Dolores García-Armario: None declared, S AntónGonzález: None declared, ANA URRUTICOECHEA-ARANA: None 